\title{
Application of Xinjiang Native Culture in Modern Design
}

\author{
Qian Sun \\ School of Art and Design \\ Xi'an University of Technology \\ Xi'an, China
}

\author{
Haibin Dong \\ School of Art and Design \\ Xi'an University of Technology \\ Xi'an, China
}

\begin{abstract}
The wide area of Xinjiang nourishes several minorities forming their own distinctive culture in life and production. Excellent native art and art modeling of various minorities provide good reference for modern artistic design. The paper conducts analyses on specific application of various minorities' native culture in Xinjiang and its influence, thus putting forward innovation and development road of Xinjiang native cultural elements.
\end{abstract}

Keywords—native Xinjiang; folk tradition; crafts culture; exploration

\section{INTRODUCTION}

Ethnic culture has a wide range, including folk fine arts, culture and art. Due to its unique modeling beauty, ethnic culture plays an important role in modern artistic design, especially that various transformation and exaggeration techniques in folk fine arts bring great visual impact, irregular changes and imaginative feelings to people when used in costume design and architectural ornament. Therefore, ethnic art in combination with modern design methods demonstrates the decisive role culture plays in design concept well and shows that ethnic culture has its own unique charm in modern art.

\section{Xinjiang Native Culture AND Modern Design}

During its development course, each country or nation gradually forms unique cultural features and living habits suitable for itself, whose unique value is mainly reflected in native culture. Therefore, art can't be separated from native culture; otherwise artistic design would drift away from the nation. Distinctive features of ethnic culture should be shown in modern design, thus enabling modern design to claim its own value in national features. China's Xinjiang area boasts native culture with unique value. Since the times of ancient Silk Road, Xinjiang, as an important area, boasts colorful eastern and western cultures exchange and blending. Various patterns with distinctive features, multi styles and graceful modeling appear in folk artistic creation and have wide application as in costume, hand ornament, life utensils and carpets as decorations. For example, carpet pattern in Kashgar boasts artistic features such as rigorous modeling and exquisite and delicate patterns with elegant and harmonious colors and its color is bright with varying patterns compared with carpets in Kuqa, reflecting the unique psychological culture and aesthetic psychology of Uighur in Xinjiang.

\section{EMBodiment OF XinJiAng NATIVE CUlture IN MODERN DESIGN}

Xinjiang minorities' culture is very different from other ethnic groups', which is determined by the unique environment people live in. Therefore, we can extract certain elements in Xinjiang native culture and apply them in modern design, thus, on the one hand, design art can be endowed with ethnic unique value and gets its artwork's cultural connotation enhanced; on the other hand, Xinjiang minorities' cultural development can be boosted. Analyzing from the perspective of production design, Xinjiang's rich ethnic culture can better enhance products' features. For example, pomegranate flower pattern in Uygur culture can be used in design of red wine's logo design. We can use the morphosis of pomegranate flower petals to create beautiful patterns, effectively reflecting modern design's integration with ethnic culture and advancing ingenious integration of Xinjiang native culture and modern design. Besides, Buddhism cavern's fresco uses "snow chrysanthemum" in Xinjiang native culture as a modeling element to decorate the figures in cavern, achieving the function of beautification and embellishment. In addition, the standard three blue and three green colors are used in the design of "Hongwan snow chrysanthemum", endowing the design with artistic value deriving from unique Xinjiang native features and reflecting the vitality of Xinjiang native culture in modern artistic design "Fig. 1". At last, Aidelaisi, the unique element in Xinjiang native culture, has wide application in modern design. For example, elements extracted from Aidelaisi can be used in fashion design, endowing fashionable dress with ethnic features. In addition, on the 60th anniversary of Xinjiang Uygur Autonomous Region's establishment in 2015, Aidelaisi design pattern is used in cover design of evening party's leaflet and in VI design of national Winter Olympic Games in 2015, showing the unique cultura connotation of Xinjiang. Through the above analysis, we can see that artistic elements in Xinjiang culture can be combined with modern technology to endow native culture with a new life. As another example, decorative "Mihe Lafu" modeling of Uyghur residents is widely applied in Xinjiang's architecture through modern art, such as Junbang Mount Tianshan Restaurant, Haier Bago Restaurant and so on "Fig. 2". Excellent native culture of Xinjiang is combined with modern 
artistic design, advancing the better and faster development of Xinjiang native culture in modern society.
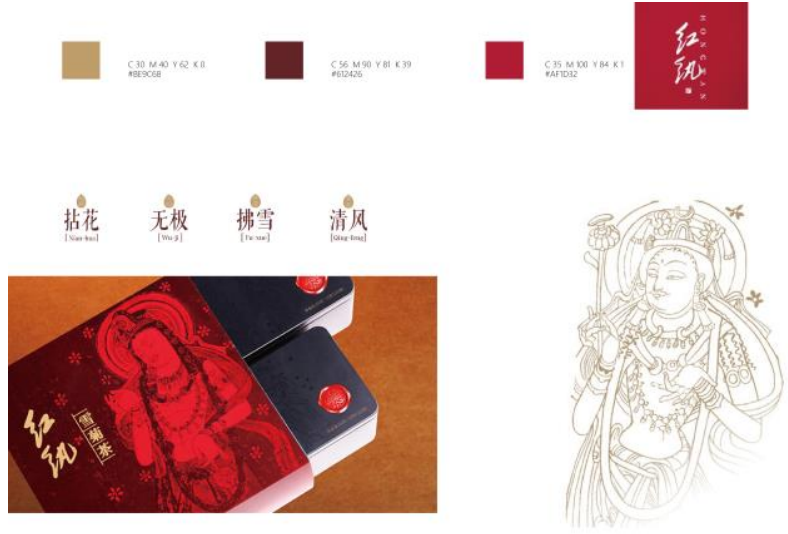

Fig. 1. Hongwan Snow Chrysanthemum Series Design.

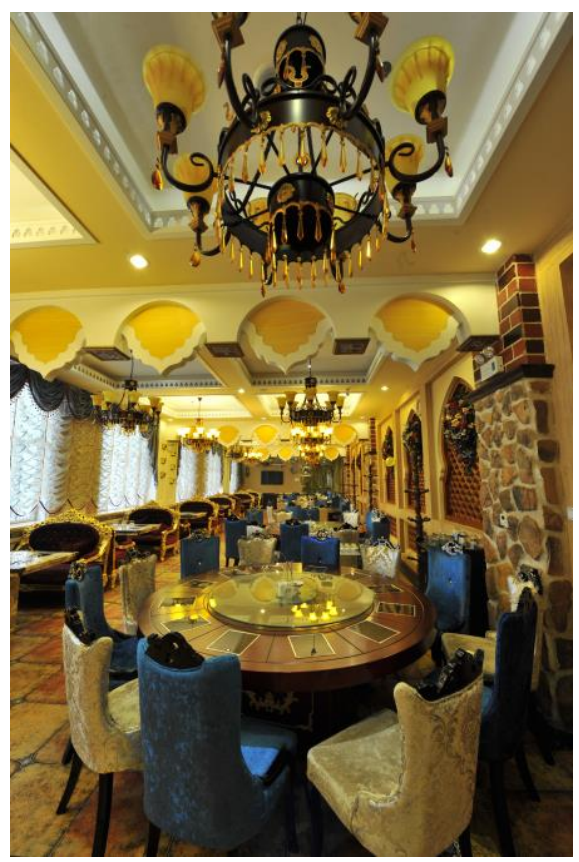

Fig. 2. Haier Bago Restaurant.

\section{Xinjiang Native Culture'S InfluenCE ON MODERN DESIGN}

Xinjiang native culture's core connotation has provided many possibilities for current artistic design. Therefore, designers should further know about, analyze, research and extract more ethnic cultural elements in modern design to better reflect ethnic cultural spirit in modern design.

First, in terms of designing Xinjiang brands, designers can find out cultural elements most suitable for current people's appreciation among the whole culture to endow modern design with new inspiration brought by Xinjiang culture. Current ethnic cultural elements and many concepts are in the stage of gradual trying, learning, collecting and sorting out and research on Xinjiang ethnic culture is still at the initial stage with many deficiencies. For example, no complete system has been formed for anthropology, semiology, science of religion and sociology. Multi-directional in-depth research on ethnic culture is required to bring more and better design elements into modern design.

Second, Xinjiang culture value hasn't produced far and wide influence on current design field especially that driven by profit, Xinjiang ethnic culture blindly expands in the market with declining commercial design quality. Therefore, relevant scholars and designers need to have a good understanding of and grasp Xinjiang ethnic cultural value forming in certain environment and place emphasis on exploring more regional features in ethnic culture and combining them with modern artistic design. Current commercial design can combine with more features in Xinjiang ethnic culture to endow people with more traditional cultural value. For example, Xinjiang Urumuqi Airline's logo is a successful case combining ethnic traditional artistic elements, reflecting Xinjiang native culture's features in perfect combination with modern artistic design. It is really a classic case applying ethnic art in modern commercial design.

Third, benefiting from China's "Belt and Road" strategic development policy, Xinjiang's economic growth has promising prospect and its unique native culture has the opportunity to burst into bloom in modern design. Under the guidance of national policy, specifically targeted poverty alleviation suggested in "The 13th Five Year Plan", more and more Xinjiang projects would facilitate Xinjiang's development and Xinjiang ethnic culture plays a role in modern design at the same time. Therefore, research by designers and scholars on Xinjiang ethnic culture can effectively boost combination of ethnic culture and modern social development. Guiding concept and design method of artistic design can be updated, and the thought on presentation and artistic appreciation of national art can be expanded gradually. Under the influence of Xinjiang's excellent ethnic culture, modern artistic design is provided with more inspirations.

Each ethnic culture boasts distinctive features and its elements can obtain better development in combination with current artistic design in constant progress and integration.

\section{DEVELOPMENT AND INNOVATION OF ETHNIC NATIVE CULTURE IN MODERN DESIGN}

Ethnic culture value needs to get merged into modern design field like advertisement, fashion design, corporate image design, space design and product packaging to obtain development of ethnic artistic culture in the current era. In addition, ethnic culture needs to combine with modern innovative representation techniques like multimedia technology and new media art to apply ethnic culture's distinctiveness in the field people get involved in. On the one side, ethnic culture art needs to absorb modern visual appreciation effects and constantly brings the integrated visual beauty of ethnic and modern art to people. On the other side, ethnic native culture needs to constantly expand its own knowledge and gradually get in line with international 
development, thus advancing better development of ethnic art through innovation.

The phenomenon of cultural spirit loss appears in modern art development and we should try to absorb the valuable part of ethnic traditional culture. Through study and research on distinctive art formed in ethnic development, including folk fine arts, we can absorb the essence in modern artistic design field and enable modern artistic design to show ethnic distinctive culture value on the grand stage of the world, which is an effective way to obtain constant development of ethnic culture.

Ethnic art can play a role in design based on its unique innovative value. For example, innovation in architectural design brings International Grand Bazaar - Xinjiang Grand Theater, which becomes the typical sign of Xinjiang's architecture, obtains international awards and wins laurel for our country. In addition, Urumqi Municipal People's Theater, Xinjiang Opera House and municipal museum combine Islamic architectural features with modern architecture in design, thus enriching local architectural style "Fig. 3". What's more, designers absorb ethnic folk art in graphic design and have bold conception to create artistic work with strong ethnic features, conforming to modern people's appreciation requirement for artwork. For example, artwork like Manas epic and Palhard and Celine, and Sun Xiuqin's minority fashion design obtain international awards. Besides, Zhang Wenge sets up a native art institute and spends a long period of time exploring Xinjiang folk art style and Islamic culture and history, contributing to the development of Xinjiang native culture. For example, his Camel and Human smartly uses ethnic patterns as decoration, showing unique artistic charm.

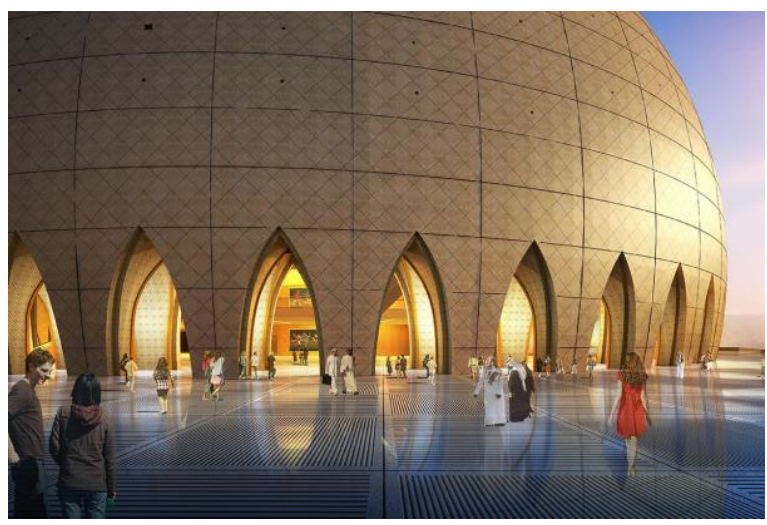

Fig. 3. Xinjiang Grand Theatre.

\section{CONCLUSION}

Through the above analysis, we can see that Xinjiang native folk arts and crafts play an inspiring role in modern design and boost the development of Xinjiang ethnic art by combination with modern principle. China's modern design needs to absorb artistic inspiration. With development of globalization, artistic integration and assimilation tend to become clearer and clearer. Therefore, we should zealously search for characteristic elements in ethnic art to bring novel and unique design inspiration and thoughts into modern design. Design art needs to absorb artistic nutrients which are the fresh blood from the reality and ethnic culture in order to achieve integration and development of modern design and Xinjiang native folk culture.

\section{REFERENCES}

[1] Liu Qiang, Sun Kai. Village Development and Renaissance under Traditional Crafts Cultural Change: Case Study on Zhoufang Ancient Village, Wenxiang, Jiangxi[J]. Urban Development Research, 2016,23(4):22.

[2] Guo Zhichao. The She Village's Variance and Development Research under the Perspective of Community Building - Wang Xiao's Review on Surpassing Huge Mountain - Social Economy Culture Change of She Ethnic Minority Group with the Surname of Zhong in Peitou Village, South Zhejiang[J]. Fuzhou University Journal(Philosophy and Social Science Edition), 2016,30(2):25-27.

[3] Yi Mingjiang - Abdureyim, Rezvanguri - Wu Qikong. Application of Xinjiang Ethnic Folk Arts Elements in Modern Native Oil Painting Creation[J]. Journal of Xinjiang Arts University, 2016,14(01):5-9.

[4] Gao Xiangdong, Zhu Beiqian, Yang Shengli. New Features and Development Trend of Population in Western Ethnic Minorities Living Area - Take Kashi, Xinjiang as an Example[J]. Population and Development, 2013,19(3):38-45.

[5] Wei Na. Xinjiang Cultural Industry and Ethnic Traditional Culture Analysis on Uyghur Folk Crafts Arts Elements on Qifang Street[J]. Modern Decoration(theory), 2014,05(01):135-136.. 